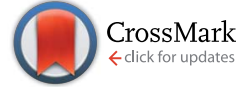

Cite this: RSC Adv., 2017, 7, 10875

Received 6th December 2016 Accepted 4th February 2017

DOI: $10.1039 / c 6 r a 27844 b$

rsc.li/rsc-advances

\title{
Ratiometric luminescence detection of hydrazine with a carbon dots-hemicyanine nanohybrid system $†$
}

\begin{abstract}
Zhen An, Zhanxian Li, ${ }^{*}$ Yangyang He, Bingjie Shi, Liuhe Wei and Mingming Yu*
It is significant to develop probes for rapid, selective, and sensitive detection of highly toxic hydrazine in both environmental and biological science. In this work, under mild conditions, through the electrostatic attraction between negatively charged CDs and positively charged hemicyanine molecules, a novel ratiometric fluorescent probe containing CDs and a hemicyanine derivative was fabricated for reliable, selective, and sensitive sensing of hydrazine. This nanohybrid system possesses dual emission peaks at 550 and $610 \mathrm{~nm}$ under a single excitation wavelength of $530 \mathrm{~nm}$. The addition of hydrazine to CDshemicyanine nanohybrid solution results in complete fluorescence quenching of the hemicyanine derivative, while the orange fluorescence of CDs remains constant. Furthermore, the CDs-hemicyanine nanohybrid system shows high selectivity toward hydrazine over other various species, including some nucleophilic species, metal ions and anions. The limit of quantification (LOQ) was 0-1 mM and the detection limit was as low as $8.0 \mu \mathrm{M}$.
\end{abstract}

\section{Introduction}

As a highly reactive base and reducing agent, hydrazine plays crucial roles in the chemical, pharmaceutical and agricultural industries. ${ }^{1-3}$ Due to its detonable characteristics, hydrazine is also a high-energy fuel for rocket-propulsion systems and missile systems. ${ }^{4}$ However, hydrazine is classed as a highly toxic and pollutant compound, which can potentially lead to serious environmental contamination during its manufacture, use, transport and disposal. In addition, as a neurotoxin, hydrazine has several mutagenic effects, which can cause damage to the liver, lungs, kidneys and central nervous system of humans. ${ }^{5-7}$ Besides, hydrazine is readily absorbed through oral, dermal or inhalation routes of exposure and it can cause harm to live cells. Due to its widespread application, easy absorbance, and high toxicity, hydrazine has been classified as a probable human carcinogen by the U.S. Environmental Protection Agency and has a low threshold limit value of $10 \mathrm{ppb}^{8}{ }^{8}$ Thus, an efficient and simple method for determining hydrazine levels is urgently needed in both environmental and biological science.

Approaches such as chromatography-mass spectrometry, titration and electrochemical methods are available to measure hydrazine, but they often require complicated equipment and sample handling and professional operating personnel.

College of Chemistry and Molecular Engineering, Zhengzhou University, Zhengzhou 450001, China. E-mail: lizx@zzu.edu.cn; yumm@zzu.edu.cn; Fax: +86 371 67781205; Tel: +8637167781205

$\uparrow$ Electronic supplementary information (ESI) available: Synthesis procedure and spectral data. See DOI: $10.1039 / \mathrm{c} 6 \mathrm{ra} 27844 \mathrm{~b}$
Therefore, it is difficult to detect trace hydrazine in situ, fast and low cost in room temperature. On the other hand, fluorescencebased method has been widely used to detect various analytes such as metal ions, anions and biomolecules due to its simplicity, high sensitivity, rapid response, capacity of real-time and in situ monitoring of the dynamic biological processes in living cells. ${ }^{9-13}$ However, available fluorescent probes for hydrazine are still very limited and most of them are turn-on types..$^{14-24}$

As we all know, the emission intensity may be influenced by many factors, such as optical path length and the illumination intensity, which are prone to disturbance in quantitative detection. In addition, when turn-on mode fluorescent probes are used in complicated biosystems, the detection is influenced by the probe concentration, autofluorescence, and instrumental factors. A ratiometric approach can eliminate the effects of these factors and realize more effective quantitative detection through measuring the ratio of fluorescence intensities at two different wavelengths. ${ }^{25}$ On the other hand, fluorescent probes could be significantly influenced by excitation power and detector sensitivity. By comparison, colorimetric probes are more suitable for direct observation with the naked eye because they are based on absorption properties of the ground state. ${ }^{26-28}$ Up to now, very few ratiometric fluorescent and colorimetric probes toward hydrazine have been reported. ${ }^{29-35}$ Therefore, it is of great interest to design ratiometric fluorescent and colorimetric probes for hydrazine.

As an ideal ratiometric fluorescent sensing mode, fluorescence resonance energy transfer (FRET) has been widely adopted in ratiometric detection because of its facile control and basis on established theory. ${ }^{36}$ For a FRET system, the use of the ratio of two interconnected fluorescence signals as the detection 

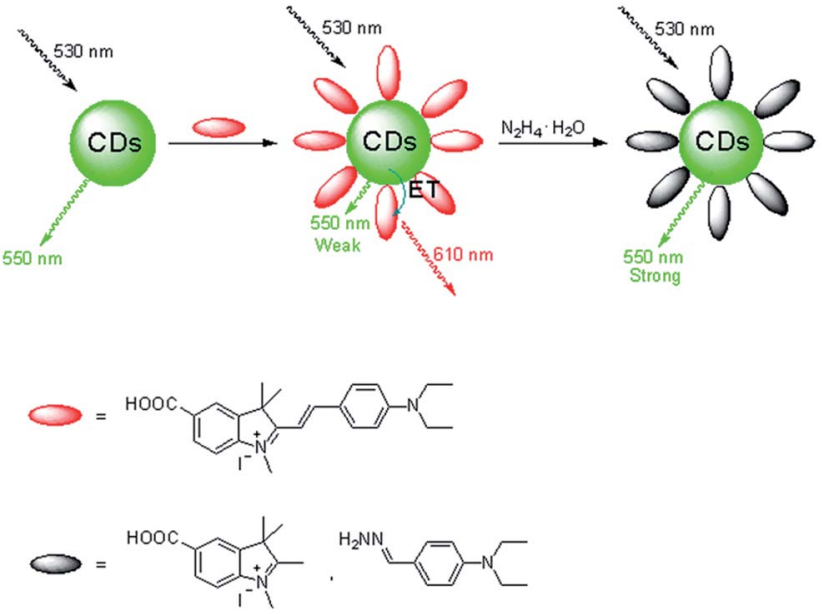

Fig. 1 Dual-emission fluorescence sensing of hydrazine based on a CDs-hemicyanine nanohybrid system.

index could effectively eliminate the background interference and the fluctuation of detection conditions. ${ }^{37,38}$

On the other hand, due to their small size, tunable surface functionalities and good photostability, carbon nanodots (CDs) have many excellent properties such as good water solubility, biocompatibility, excellent cell membrane permeability and low cost. ${ }^{39-43}$ Such features make CDs especially useful for fluorescent biosensing or imaging: ${ }^{4-48}$ However, exploration of CDs as fluorescent probes still remains at an early stage and no reports about CDs fluorescent probe toward hydrazine has been reported.

In this paper, we describe the first example of a FRET-based CDs-hemicyanine nanohybrid ratiometric probe toward hydrazine. In this probe, the CDs not only serve as the energy donor, but also as the anchoring site for the probe, a hemicyanine derivative. The schematic illustration for the selective detection of hydrazine by the CDs-hemicyanine probe is shown in Fig. 1 . The probe based on this CDs-hemicyanine architecture demonstrates several advantages: it is a FRET-based ratiometric probe toward hydrazine which can ensure more accurate detection with a detection limit of $8 \mu \mathrm{M}$, and it also has a large shift $(80 \mathrm{~nm})$ between donor excitation and acceptor emission, which rules out any influence of excitation backscattering effects on fluorescence detection. Moreover, due to the $\lambda_{\mathrm{ex}}$-dependent PL emission of the CDs, we can readily control the emission wavelength of the donor (CDs) and allow for precise energy matching between the donor and the acceptor of the FRET system, which is beneficial to detection accuracy.

\section{Results and discussions}

\section{Synthesis of probe 1 and preparation of CDs}

For the fabrication of the sensing system, first we synthesized amino and carboxyl coated CDs by a simple hydrothermal method using citric acid and ethylenediamine as the precursors. Fig. 2a indicates the TEM image of as-prepared CDs. Well-resolved lattice fringes are observed in high-resolution TEM (HRTEM, Fig. 2b) image. The diameter distribution of the CDs is about $2.72 \mathrm{~nm}$ and the zeta potential is $-30.4 \mathrm{mV}$ (Fig. 2c), which is ascribed to the
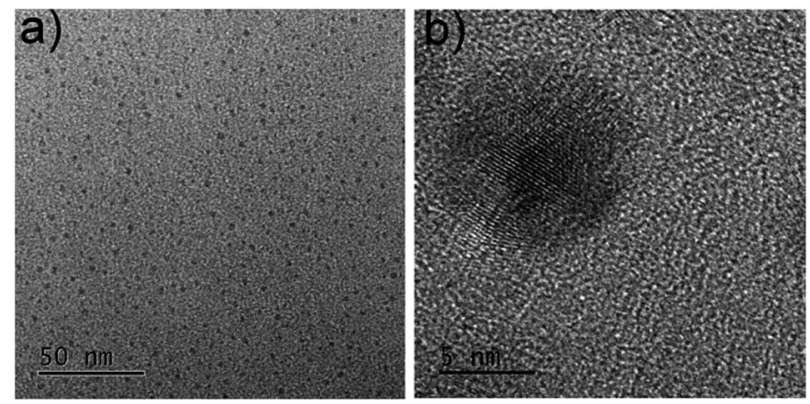

c)

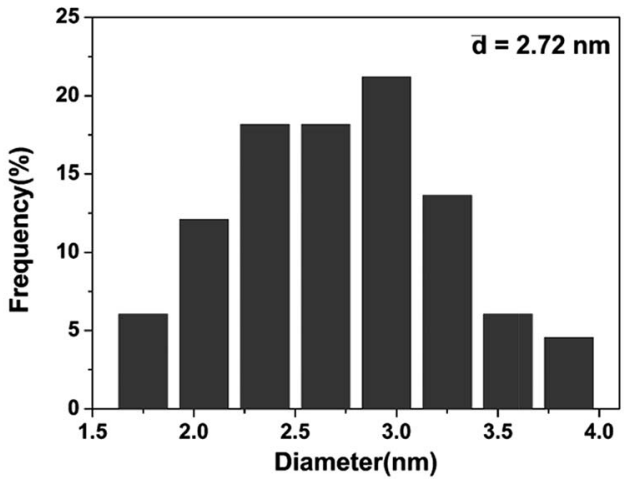

Fig. 2 (a) TEM image of the as-prepared CDs, (b) HRTEM image of the as-prepared CDs, (c) diameter distribution of the as-prepared CDs.

surface negative electricity of the CDs. FT-IR spectra (Fig. S1 in ESI $\dagger$ ) reveal that the CDs mainly contain carbon, nitrogen, oxygen, and the surfaces of the CDs are functionalized with amino, hydroxyl, and carboxylic/carbonyl moieties.

Hemicyanine derivative $\mathbf{1}$ was selected as the sensing unit and energy accepter, which was synthesized in a high yield starting from $p$-hydrazinobenzoic acid hydrochloride through three steps. The reaction of $p$-hydrazinobenzoic acid hydrochloride and dimethylacetone gives product 3 . Compound 2 was obtained with a yield of $44.7 \%$ by the reaction of compound 3 and $\mathrm{CH}_{3} \mathrm{I}$. The reaction of 2 and 4-diethylaminobenzaldehyde gives product 1 in a yield of $31.6 \%$. Probe 1 was characterized by ${ }^{1} \mathrm{H}$ NMR, ${ }^{13} \mathrm{C}$ NMR and HRMS.

\section{Hydrazine sensing properties}

Fig. 3a and $\mathrm{b}$ and present the absorption and fluorescence spectra of probe 1 upon addition of hydrazine. It was clear that the absorbance at about $577 \mathrm{~nm}$ and emission at $610 \mathrm{~nm}$ decreased dramatically in the presence of hydrazine and completely disappeared when the concentration of hydrazine was up to $1 \mathrm{mM}$. The absorption and fluorescence spectra change of probe 1 by hydrazine is presumably due to the reaction of probe 1 and hydrazine. However, the emission spectrum of the CDs hardly changes upon addition of hydrazine, and the slight change was presumably due to electron/hole annihilation through effective electron or energy transfer process, which resulted from the strong electrostatic interaction between CDs and hydrazine (Fig. 3c). Prior to probe preparation, the interaction between CDs and probe 1 in the hybrid system was first investigated by monitoring their absorption and fluorescence spectra changes. As shown in Fig. 3d, the maximum absorption 

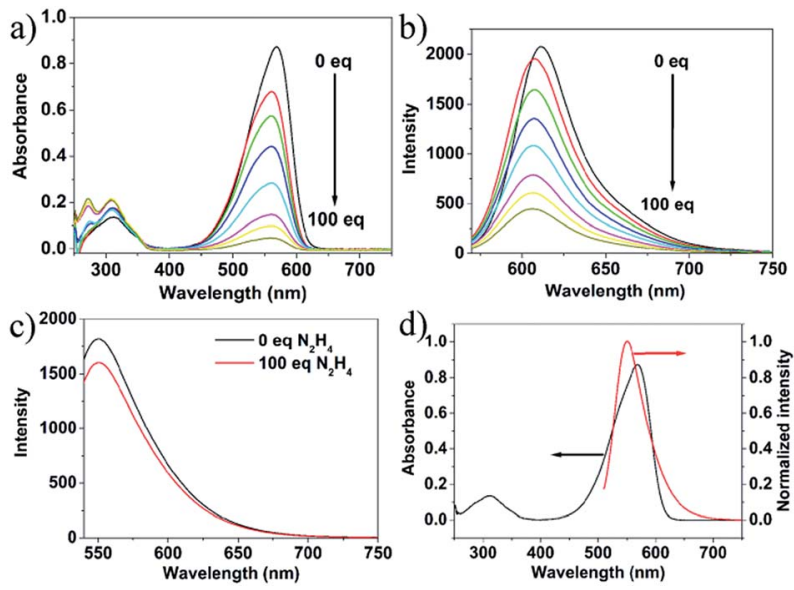

Fig. 3 Absorption (a) and fluorescence (b) titration spectra of probe 1 $\left(1.0 \times 10^{-5} \mathrm{M}, V_{\text {DMSO }} / V_{\text {water }}=9 / 1\right)$ upon gradual addition of hydrazine from 0 to $1 \mathrm{mM}$. (c) Fluorescence spectra change of CDs (water, $0.01 \mathrm{mg}$ $\left.\mathrm{mL}^{-1}\right)$ with excitation at $530 \mathrm{~nm}$. (d) Absorption of probe $1\left(1.0 \times 10^{-5} \mathrm{M}\right.$, $V_{\text {DMSO }} / V_{\text {water }}=9 / 1$ ) (black line) and fluorescence spectrum of CDs (water, $0.01 \mathrm{mg} \mathrm{mL}^{-1}$ ) with excitation at $530 \mathrm{~nm}$ (red line).

peak of probe 1 is at about $577 \mathrm{~nm}$ and the emission peak of CDs is at about $550 \mathrm{~nm}$ upon excitation at $530 \mathrm{~nm}$. That is to say, there is a good overlap between the absorption spectrum of probe $\mathbf{1}$ and the PL spectrum of CDs, indicating that the energy transfer efficiency from CDs to probe $\mathbf{1}$ may be high. Therefore, it is possible to select a $530 \mathrm{~nm}$ wavelength laser to excite CDs in the hybrid probe. Upon $530 \mathrm{~nm}$ excitation, the emission of CDs was absorbed by probe 1 and the nanohybrid system exhibits one very strong emission peak at $610 \mathrm{~nm}$ and a very weak emission peak at $550 \mathrm{~nm}$. To obtain a ratiometric fluorescence probe with an appropriate color variation during sensing, we prepared a mixture solution containing $\mathrm{CDs}\left(0.01 \mathrm{mg} \mathrm{mL}^{-1}\right)$ and probe 1 $(10 \mu \mathrm{M})$ as the probe solution for hydrazine detection.

To study the sensing properties of the CDs-hemicyanine nanohybrid system toward hydrazine, UV-Vis and fluorescence titration experiments (Fig. 4) were conducted with $0-1 \mathrm{mM}$ hydrazine water solution in aqueous solution of CDs-hemicyanine nanohybrid system $\left(V_{\text {water }} / V_{\text {DMSO }}=1 / 9\right)$. Upon addition of hydrazine, the absorbance at $561 \mathrm{~nm}$ in the UV-Vis spectra decreased gradually with the original peak at $317 \mathrm{~nm}$ changing a little, and then, the peak at $561 \mathrm{~nm}$ reached the minimum at 100 equiv. of hydrazine (Fig. 4a). Accordingly, upon excitation at $530 \mathrm{~nm}$, the emission intensity at $610 \mathrm{~nm}$ decreased and that at $550 \mathrm{~nm}$ increased with increasing hydrazine concentration (Fig. 4b). The decrease of the absorption peak at $561 \mathrm{~nm}$ and that at $610 \mathrm{~nm}$ in emission spectrum is ascribed to the reaction of hydrazine and probe 1 . The increase of the emission peak at $550 \mathrm{~nm}$ can be explained as below: upon excitation at $530 \mathrm{~nm}$ and with no hydrazine, the emission at $550 \mathrm{~nm}$ of the CDs was mostly absorbed by probe 1 and gave a strong emission at $610 \mathrm{~nm}$; with the addition of hydrazine, a new compound was obtained, which cannot absorb energy at $550 \mathrm{~nm}$ and no emission at $610 \mathrm{~nm}$ was given, thus, the emission at $550 \mathrm{~nm}$ increased and that at $610 \mathrm{~nm}$ decreased. Moreover, the solution color of $\mathbf{1}$ changed by degrees from pink to colorless in the presence of different concentrations
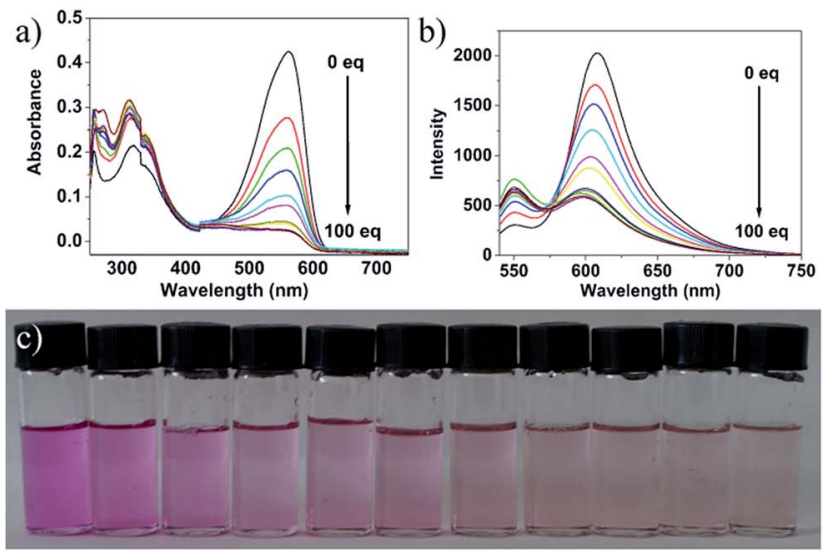

d)

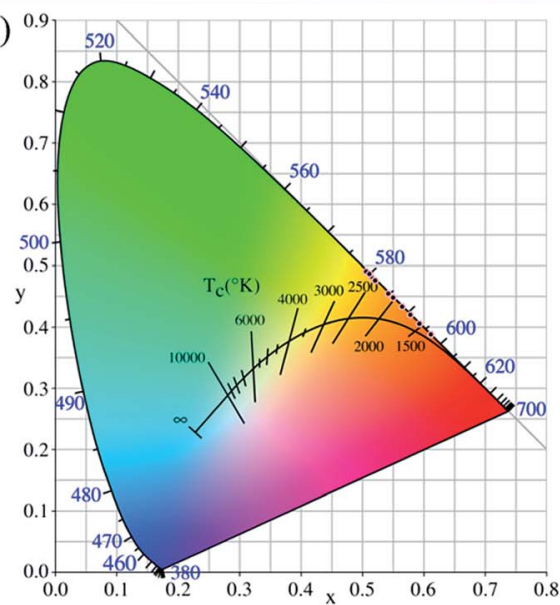

Fig. 4 (a) Absorption and (b) emission spectra of the CDs-hemicyanine nanohybrid system $\left[V_{\text {water }} / V_{\mathrm{DMSO}}=1 / 9\right]$ upon titration of hydrazine water solution (0-100 equiv. to 1) with excitation at $530 \mathrm{~nm}$. The reaction time is 60 min hydrazine concentration from left to right: $0 \mathrm{M}, 1.0 \times 10^{-4} \mathrm{M}, 2.0 \times 10^{-4} \mathrm{M}, 3.0 \times 10^{-4} \mathrm{M}, 4.0 \times 10^{-4} \mathrm{M}, 5.0 \times$ $10^{-4} \mathrm{M}, 6.0 \times 10^{-4} \mathrm{M}, 7.0 \times 10^{-4} \mathrm{M}, 8.0 \times 10^{-4} \mathrm{M}, 9.0 \times 10^{-4} \mathrm{M}, 1.0 \times$ $10^{-3} \mathrm{M}$. Photographs of the CDs-hemicyanine nanohybrid system $\left[V_{\text {water }} / V_{\mathrm{DMSO}}=1 / 9\right]$ upon addition of hydrazine at various concentrations $\left(0 \mathrm{M}, 1.0 \times 10^{-4} \mathrm{M}, 2.0 \times 10^{-4} \mathrm{M}, 3.0 \times 10^{-4} \mathrm{M}, 4.0 \times 10^{-4} \mathrm{M}\right.$, $5.0 \times 10^{-4} \mathrm{M}, 6.0 \times 10^{-4} \mathrm{M}, 7.0 \times 10^{-4} \mathrm{M}, 8.0 \times 10^{-4} \mathrm{M}, 9.0 \times 10^{-4} \mathrm{M}$, $1.0 \times 10^{-3} \mathrm{M}$, from left to right) in water in daylight (c). The reaction time is $20 \mathrm{~min}$. (d) CIE 1931 ( $x, y)$ chromaticity diagram of the solutions for the detection of hydrazine at different concentrations.

of hydrazine (Fig. 4c). The Commission Internationale de L'Eclairage (CIE) $1931(x, y)$ chromaticity diagram of the solutions after addition of different concentrations of hydrazine for 30 minutes are shown in Fig. $4 \mathrm{~d}$. When the hydrazine concentration was increased, the fluorescence color of the solution changed from red to orange. All of the above spectra, solution and fluorescence color change implied that probe $\mathbf{1}$ can serve as not only a highly sensitive 'naked-eye' probe but also a ratiometric fluorescence probe for hydrazine.

Fig. 5a suggested a good linear relationship between the ratio of $I_{550} / I_{610}$ with hydrazine concentration in the range of 0 and $1 \mathrm{mM}$, implying that hydrazine can be quantitatively detected in a wide concentration range in ratiometric fluorescence mode. From the linear calibration graph with the fluorescence titration experiment (Fig. 5a), the detection limit of probe CDs-hemicyanine for hydrazine was figured out to be about $8.0 \mu \mathrm{M}$ based 

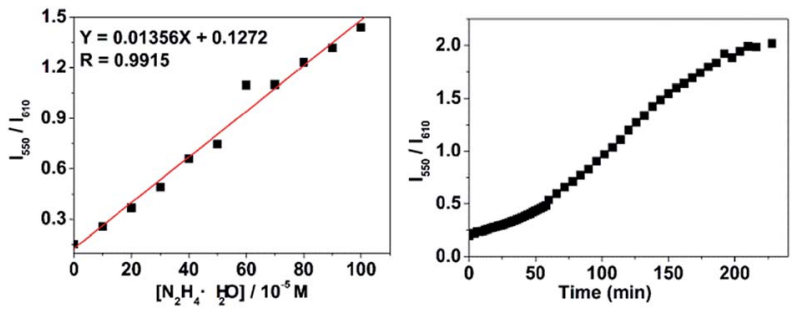

Fig. 5 The linearity of emission intensity of the CDs-hemicyanine nanohybrid system $\left(V_{\text {water }} / V_{\text {DMSO }}=1 / 9\right)$ with respect to hydrazine concentrations. The excitation wavelength was $530 \mathrm{~nm}$ and the reaction time is $60 \mathrm{~min}$ (a). Kinetics of fluorescence change rate by the reaction of the CDs-hemicyanine nanohybrid system $\left[V_{\text {water }} / V_{\text {DMSO }}=\right.$ 1/9] and hydrazine (the concentration of hydrazine is $\left.1.0 \times 10^{-3} \mathrm{M}\right)(\mathrm{b})$. $I_{550}$ and $I_{610}$ represent the emission intensity at $550 \mathrm{~nm}$ and $610 \mathrm{~nm}$.

on signal-to-noise ratio $(\mathrm{S} / \mathrm{N})=3 .^{49,50}$ These results led us to conclude that CDs-hemicyanine nanohybrid system could be an effective ratiometric fluorescent probe for hydrazine.

Time-dependent fluorescence experiments on the CDs-hemicyanine nanohybrid system toward hydrazine the CDs-hemicyanine nanohybrid system hydrazine is completely accomplished within $190 \mathrm{~min}$ and hydrazine can be detected within $60 \mathrm{~min}$ when the concentration of hydrazine is higher or equal to $1.0 \times 10^{-3} \mathrm{M}$.

\section{The sensing mechanism}

The sensing mechanism was studied by mass spectra. For pure probe 1 , a characteristic peak at $m / z=3777.2227$ was obtained which corresponds to the species [M $-\mathrm{I}]$, whilst on reaction of hydrazine, the peak at 3777.2224 disappeared and one new peak appeared at $m / z=192.1499$ corresponding to the species [ $4+\mathrm{H}$ ]. Such mass spectra data confirm that compound $\mathbf{4}$ was formed through the reaction of hydrazine with probe $\mathbf{1}$ (Scheme 1).

The selectivity study of the CDs-hemicyanine nanohybrid system for hydrazine

To evaluate the selectivity of the CDs-hemicyanine nanohybrid system for hydrazine, various species including some biological

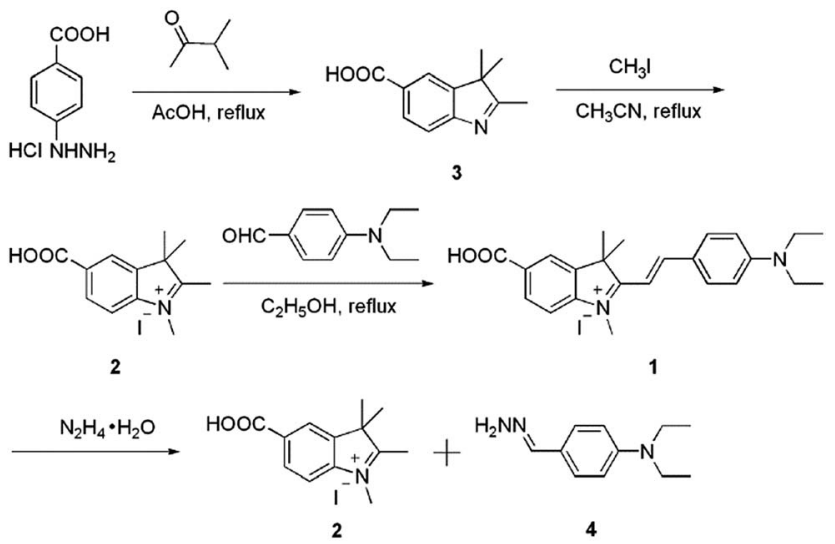

Scheme 1 Synthesis of the probe 1 and the proposed mechanism of the response of 1 to hydrazine.

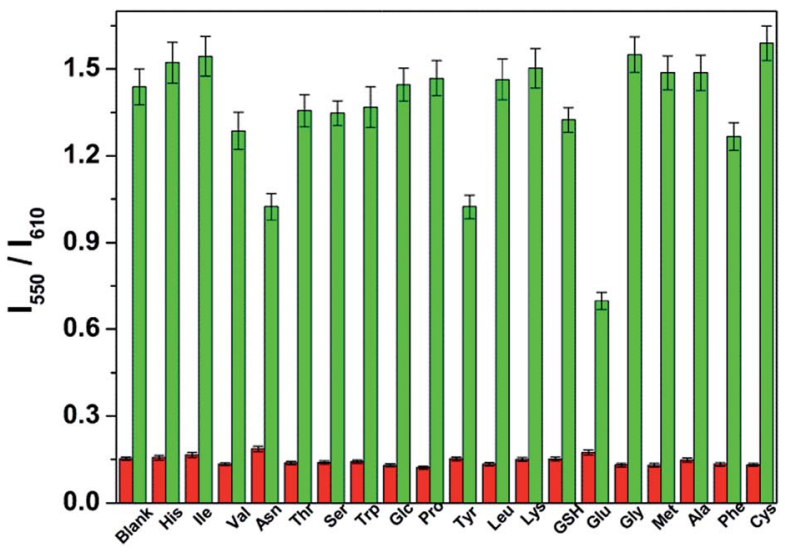

Fig. 6 Fluorescence response (red bars) of the CDs-hemicyanine nanohybrid system $\left(V_{\text {water }} / V_{\text {DMSO }}=1 / 9\right)$ upon addition of different species (100 equiv. of species relative to 1 ), and fluorescence changes (green bars) of the mixture of the CDs-hemicyanine nanohybrid system $\left(V_{\text {water }} / V_{\text {DMSO }}=1 / 9\right)$ and hydrazine hydrate $(1 \mathrm{mM}$ in water $)$ after addition of an excess of the indicated species (100 equiv. relative to 1) (green bars). The excitation wavelength was $530 \mathrm{~nm}$ and the reaction time was $60 \mathrm{~min}$. $I_{550}$ and $I_{610}$ represent the emission intensity at $550 \mathrm{~nm}$ and $610 \mathrm{~nm}$. The species used were His, lle, Val, Asn, Thr, Ser, Trp, Glc, Pro, Tyr, Leu, Lys, GSH, Glu, Gly, Met, Ala, Phe, Cys.

species (His, lle, Val, Asn, Thr, Ser, Trp, Glc, Pro, Tyr, Leu, Lys, $\mathrm{GSH}$, Glu, Gly, Met, Ala, Phe, Cys), various metal ions $\left(\mathrm{Na}^{+}\right.$, $\mathrm{Mg}^{2+}, \mathrm{Al}^{3+}, \mathrm{K}^{+}, \mathrm{Ca}^{2+}, \mathrm{Cr}^{3+}, \mathrm{Mn}^{2+}, \mathrm{Fe}^{3+}, \mathrm{Co}^{2+}, \mathrm{Ni}^{2+}, \mathrm{Cu}^{2+}, \mathrm{Zn}^{2+}$, $\left.\mathrm{Cd}^{2+}, \mathrm{Hg}^{2+}, \mathrm{Pb}^{2+}\right)$ and anions $\left(\mathrm{CH}_{3} \mathrm{COO}^{-}, \mathrm{SO}_{4}{ }^{2-}, \mathrm{SO}_{3}{ }^{2-}, \mathrm{HS}^{-}\right.$, $\mathrm{S}_{2} \mathrm{O}_{3}{ }^{2-}, \mathrm{S}_{2}{ }^{-}, \mathrm{P}_{2} \mathrm{O}_{7}{ }^{4-}, \mathrm{NO}_{3}{ }^{-}, \mathrm{N}_{3}{ }^{-}, \mathrm{I}^{-}, \mathrm{HSO}_{4}{ }^{-}, \mathrm{HSO}_{3}{ }^{-}, \mathrm{HPO}_{4}{ }^{2-}$, $\mathrm{HCO}_{3}{ }^{-}, \mathrm{H}_{2} \mathrm{PO}_{4}{ }^{-}, \mathrm{F}^{-}, \mathrm{ClO}_{4}{ }^{-}, \mathrm{ClO}_{3}{ }^{-}, \mathrm{Cl}^{-}, \mathrm{C}_{2} \mathrm{O}_{4}{ }^{2-}$, and $\mathrm{Br}^{-}$) were tested. As shown in the red bars of Fig. 6, S3 and S4 in the ESI, $\dagger$ only the introduction of hydrazine to the CDs-hemicyanine nanohybrid system solution induced a significant fluorescence change. In the same condition, other tested species mentioned above did not induce any obvious fluorescence change to the CDs-hemicyanine nanohybrid system solution.

The anti-disturbance effect study of the CDs-hemicyanine nanohybrid system for hydrazine detection

To further assess its utility as a hydrazine-selective ratiometric fluorescent probe, its fluorescence spectral response to hydrazine in the presence of other species mentioned above (green bars of Fig. 6, S3 and $\mathrm{S} 4 \dagger$ ) was also tested. The results demonstrated that all of the selected species have no interference in the detection of hydrazine except some metal ions such as $\mathrm{Mg}^{2+}$, $\mathrm{Al}^{3+}, \mathrm{Ca}^{2+}, \mathrm{Cr}^{3+}, \mathrm{Fe}^{3+}, \mathrm{Co}^{2+}, \mathrm{Cu}^{2+}, \mathrm{Zn}^{2+}, \mathrm{Cd}^{2+}, \mathrm{Hg}^{2+}$ and $\mathrm{Pb}^{2+}$. This result strongly indicates that the CDs-hemicyanine nanohybrid system could be an excellent ratiometric fluorescent probe towards hydrazine with strong anti-interference ability.

\section{Experimental section}

\section{Materials and methods}

p-Hydrazinobenzoic acid hydrochloride, dimethylacetone, $\mathrm{CH}_{3} \mathrm{I}$, AcOH, AcONa, 4-diethylaminobenzaldehyde, His, lle, Val, Asn, Thr, Ser, Trp, Glc, Pro, Tyr, Leu, Lys, GSH, Glu, Gly, Met, 
Ala, Phe, Cys, $\mathrm{NaCl}, \mathrm{MgCl}_{2}, \mathrm{AlCl}_{3}, \mathrm{KNO}_{3}, \mathrm{CaCl}_{2}, \mathrm{CrCl}_{3}, \mathrm{MnCl}_{2}$, $\mathrm{FeCl}_{3}, \mathrm{CoCl}_{2}, \mathrm{NiCl}_{2}, \mathrm{CuCl}_{2}, \mathrm{ZnCl}_{2}, \mathrm{CdCl}_{2}, \mathrm{HgCl}_{2}, \mathrm{~Pb}\left(\mathrm{NO}_{3}\right)_{2}$, $\mathrm{CH}_{3} \mathrm{COONa}, \mathrm{Na}_{2} \mathrm{SO}_{3}, \mathrm{NaHS}, \mathrm{Na}_{2} \mathrm{~S}_{2} \mathrm{O}_{3}, \mathrm{NaS}_{2}, \mathrm{Na}_{4} \mathrm{P}_{2} \mathrm{O}_{7}, \mathrm{NaN}_{3}, \mathrm{KI}$, $\mathrm{NaHSO}_{4}, \mathrm{NaHSO}_{3}, \mathrm{Na}_{2} \mathrm{HPO}_{4}, \mathrm{NaHCO}_{3}, \mathrm{NaH}_{2} \mathrm{PO}_{4}, \mathrm{NaF}, \mathrm{NaClO}_{4}$, $\mathrm{NaClO}_{3}, \mathrm{Na}_{2} \mathrm{C}_{2} \mathrm{O}_{4}$, and $\mathrm{KBr}$. All commercial grade chemicals and solvents were purchased and were used without further purification. Mass spectra were obtained on high resolution mass spectrometer (IonSpec4.7 Tesla FTMS-MALDI/DHB). ${ }^{1} \mathrm{H}$ and ${ }^{13} \mathrm{C}$ NMR spectra were recorded on a Bruker 400 NMR spectrometer. Chemical shifts are reported in parts per million using tetramethylsilane (TMS) as the internal standard. All spectral characterizations were carried out in HPLC-grade solvents at $20{ }^{\circ} \mathrm{C}$ within a $10 \mathrm{~mm}$ quartz cell. UV-Vis absorption spectra were measured with a TU-1901 double-beam UV-Vis spectrophotometer. Fluorescence spectroscopy was determined on a Hitachi F-4600 spectrometer. Fourier transform infrared spectroscopy (FTIR) was performed on a NEXUS-470 spectrometer at frequencies ranging from 400 to $4000 \mathrm{~cm}^{-1}$. Samples for transmission electron microscopy (TEM) analysis were prepared by drying a colloidal solution of nanoparticles on amorphous carbon-coated copper grids. Low-resolution TEM were operated on a JEOL-JEM 2100 transmission electron microscopy operated at $200 \mathrm{kV}$. High resolution TEM (HRTEM) were carried out on a JEOL-JEM 2100F field emission transmission electron microscope operated at $200 \mathrm{kV}$. The particle size and zeta potential of the CDs $\left(0.5 \mathrm{mg} \mathrm{mL}^{-1}\right)$ were recorded on a zetasizer (Nanoplus3, Micromeritics, the United States).

Probe 1 was synthesized according to Scheme 1. Compounds 3 and 2 were obtained following the recently reported method. ${ }^{51}$

Synthesis of compound 2. Compound $3(1.0 \mathrm{~g}, 4.93 \mathrm{mmol})$ and $\mathrm{CH}_{3} \mathrm{I}(700 \mathrm{mg}, 4.93 \mathrm{mmol}$ ) were dissolved in $10 \mathrm{~mL}$ acetonitrile. The mixture was refluxed for 12 hours and then allowed to cool to room temperature. By filtration of the above mixture, the solid was obtained as product $2(0.76 \mathrm{~g}, 44.7 \%)$ : ${ }^{1} \mathrm{H}$ NMR (400 MHz, DMSO- $d_{6}$, TMS): $\delta_{\mathrm{H}} 8.38(\mathrm{~s}, 1 \mathrm{H}), 8.19$ $(\mathrm{d}, 1 \mathrm{H}), 8.03(\mathrm{~d}, 21 \mathrm{H}), 4.00(\mathrm{~s}, 3 \mathrm{H}), 2.82(\mathrm{~s}, 3 \mathrm{H}), 1.57$ (sd, 6H). ${ }^{13} \mathrm{C}$ NMR $\left(100 \mathrm{MHz}\right.$, DMSO- $\left.d_{6}\right): \delta_{\mathrm{C}} 199.48,166.95,142.42$, 141.72 , 132.04, 130.83, 124.68, 115.85, 54.72, 35.52, 21.96, and 15.12 .

Synthesis of probe 1 (ref. 52). Compound 2 (690 mg, 2.0 $\mathrm{mmol}$ ), and 4-diethylaminobenzaldehyde (354 mg, $2.0 \mathrm{mmol}$ ) were dissolved in $10 \mathrm{~mL}$ ethanol. The mixture was refluxed for $3 \mathrm{~h}$ at $80{ }^{\circ} \mathrm{C}$ and cooled to room temperature. The final product (probe 1, $318.6 \mathrm{mg}, 31.6 \%$ ) was obtained by filtration and being washed with ethanol for three times. Characterization of $\mathbf{1}$ : HRMS (EI) $m / z$ : calcd for $\mathrm{C}_{24} \mathrm{H}_{30} \mathrm{IN}_{2} \mathrm{O}_{2}[\mathrm{M}-\mathrm{I}]$, 3777.2224; found, 377.2227. ${ }^{1} \mathrm{H}$ NMR (400 MHz, DMSO- $\left.d_{6}, \mathrm{TMS}\right): \delta_{\mathrm{H}} 13.09(\mathrm{~s}, 1 \mathrm{H})$, 8.37 (d, 1H), $8.29(\mathrm{~s}, 1 \mathrm{H}), 8.10(\mathrm{~d}, 3 \mathrm{H}), 7.74(\mathrm{~d}, 1 \mathrm{H}), 7.22(\mathrm{~d}, 1 \mathrm{H})$, $6.91(\mathrm{~d}, 2 \mathrm{H}), 3.94(\mathrm{~s}, 3 \mathrm{H}), 3.59(\mathrm{q}, 4 \mathrm{H}), 1.78(\mathrm{~s}, 6 \mathrm{H}), 1.20(\mathrm{t}, 6 \mathrm{H}) \cdot{ }^{13} \mathrm{C}$ NMR $\left(100 \mathrm{MHz}\right.$, DMSO- $\left.d_{6}\right): \delta_{\mathrm{C}} 180.75,167.25,155.57,153.64$, $146.07,142.94,130.86,129.71,123.97,122.82$, 113.55, 112.77, 104.86, 50.97, 45.09, 33.51, 26.78, and 13.08.

\section{Preparation and characterizations of the fluorescent CDs}

CDs were prepared by hydrothermal treatment of citric acid and ethylenediamine following the reported method. ${ }^{53-55}$

\section{Absorption and fluorescence assay of hydrazine}

The detection of hydrazine was performed in the mixture of DMSO and water solution $\left(V_{\mathrm{DMSO}} / V_{\text {water }}=9 / 1\right)$ at room temperature. In a typical run, $30 \mu \mathrm{L}$ of CDs dispersion solution $\left(1 \mathrm{mg} \mathrm{mL}{ }^{-1}\right)$ was added into $3 \mathrm{~mL}$ mixed solution mentioned above in the presence of $10 \mu \mathrm{M}$ probe 1 , followed by the addition of calculated amount of hydrazine. The sensitivity and selectivity measurements were conducted in triplicate.

\section{Conclusions}

A novel ratiometric fluorescent probe containing CDs and a hemicyanine derivative was fabricated for reliable, selective, and sensitive sensing of hydrazine. The probe was built through the electrostatic attraction between negatively charged CDs and positively charged hemicyanine molecule. This nanohybrid system possesses dual emission peaks at 550 and $610 \mathrm{~nm}$ under a single excitation wavelength of $530 \mathrm{~nm}$. The addition of hydrazine to CDs-hemicyanine nanohybrid solution results in complete fluorescence quenching of the hemicyanine derivative 1, while the orange fluorescence of CDs keeps constant. Furthermore, the CDs-hemicyanine nanohybrid system shows high selectivity toward hydrazine over other various species including some biological species, metal ions and anions.

\section{Acknowledgements}

We are grateful for the financial supports from National Natural Science Foundation of China (21601158 and U1504203), Key Laboratory of Photochemical Conversion and Optoelectronic Materials and Zhengzhou University.

\section{Notes and references}

1 J. Sanabria-Chinchilla, K. Asazawa, T. Sakamoto, K. Yamada, H. Tanaka and P. Strasser, J. Am. Chem. Soc., 2011, 133, 54255431.

2 T. Sakamoto, K. Asazawa, J. Sanabria-Chinchilla, U. Martinez, B. Halevi, P. Atanassov, P. Strasser and H. Tanaka, J. Power Sources, 2014, 247, 605-611.

3 A. Serov, M. Padilla, A. J. Roy, P. Atanassov, T. Sakamoto, K. Asazawa and H. Tanaka, Angew. Chem., Int. Ed., 2014, 53, 10336-10339.

4 A. D. Sutton, A. K. Burrell, D. A. Dixon, E. B. Garner, J. C. Gordon, T. Nakagawa, K. C. Ott, P. Robinson and M. Vasiliu, Science, 2011, 331, 1426-1429.

5 R. Ahmad, N. Tripathy, D. U. J. Jung and Y. B. Hahn, Chem. Commun., 2014, 50, 1890-1893.

6 S. D. Zelnick, D. R. Mattie and P. C. Stepaniak, Aviat., Space Environ. Med., 2003, 74, 1285-1291.

7 Y. Qian, J. Lin, L. J. Han, L. Lin and H. L. Zhu, Biosens. Bioelectron., 2014, 58, 282-286.

8 A. Umar, M. M. Rahman, S. H. Kim and Y.-B. Hahn, Chem. Commun., 2008, 166-168.

9 M. H. Lee, J. S. Kim and J. L. Sessler, Chem. Soc. Rev., 2015, 44, 4185-4191. 
10 X. H. Qian and Z. C. Xu, Chem. Soc. Rev., 2015, 44, 4487-4493.

11 L. Y. Niu, Y. Z. Chen, H. R. Zheng, L. Z. Wu, C. H. Tung and Q. Z. Yang, Chem. Soc. Rev., 2015, 44, 6143-6160.

12 Q. Q. Wan, S. M. Chen, W. Shi, L. H. Li and H. M. Ma, Angew. Chem., Int. Ed., 2014, 53, 10916-10920.

13 K. Chen, Q. H. Shu and M. Schmittel, Chem. Soc. Rev., 2015, 44, 136-160.

14 M. H. Lee, B. Yoon, J. S. Kim and J. L. Sessler, Chem. Sci., 2013, 4, 4121-4126.

15 L. Cui, Z. Peng, C. Ji, J. Huang, D. Huang, J. Ma, S. Zhang, X. Qian and Y. Xu, Chem. Commun., 2014, 50, 1485-1487.

16 D. Zhou, Y. Wang, J. Jia, W. Yu, B. Qu, X. Li and X. Sun, Chem. Commun., 2015, 51, 10656-10659.

17 M. Sun, J. Guo, Q. Yang, N. Xiao and Y. Li, J. Mater. Chem. B, 2014, 2, 1846-1851.

18 M. G. Choi, J. Hwang, J. O. Moon, J. Sung and S.-K. Chang, Org. Lett., 2011, 13, 5260-5263.

19 Y. H. Xiao, G. Xi, X. X. Zhao, S. Zhou, Z. Q. Zhou and B. X. Zhao, J. Fluoresc., 2015, 25, 1023-1029.

20 K. Vijay, C. Nandi and S. D. Samant, RSC Adv., 2014, 4, 30712-30717.

21 S. I. Reja, N. Gupta, V. Bhalla, D. Kaur, S. Arora and M. Kumar, Sens. Actuators, B, 2016, 222, 923-929.

22 B. Chen, X. Sun, X. Li, H. Agren and Y. Xie, Sens. Actuators, B, 2014, 199, 93-100.

23 B. Liu, Q. Liu, M. Shah, J. Wang, G. Zhang and Y. Pang, Sens. Actuators, B, 2014, 202, 194-200.

24 M. G. Choi, J. O. Moon, J. Bae, J. W. Lee and S. K. Chang, Org. Biomol. Chem., 2013, 11, 2961-2965.

25 X. H. Li, X. H. Gao, W. Shi and H. M. Ma, Chem. Rev., 2014, 114, 590-659.

26 Z. Li, X. Liu, W. Zhao, S. Wang, W. Zhou, L. Wei and M. Yu, Anal. Chem., 2014, 86, 2521-2525.

27 M. Lan, J. Wu, W. Liu, W. Zhang, J. Ge, H. Zhang, J. Sun, W. Zhao and P. Wang, J. Am. Chem. Soc., 2012, 134, 66856694.

28 M. Lan, W. Liu, Y. Wang, J. Ge, J. Wu, H. Zhang, J. Chen, W. Zhang and P. Wang, ACS Appl. Mater. Interfaces, 2013, 5, 2283-2288.

29 J. Fan, W. Sun, M. Hu, J. Cao, G. Cheng, H. Dong, K. Song, Y. Liu, S. Sun and X. Peng, Chem. Commun., 2012, 48, 8117-8119.

30 C. Hu, W. Sun, J. Cao, P. Gao, J. Wang, J. Fan, F. Song, S. Sun and X. Peng, Org. Lett., 2013, 15, 4022-4025.

31 S. Goswami, S. Paul and A. Manna, New J. Chem., 2015, 39, 2300-2305.

32 S. Goswami, K. Aich, S. Das, S. B. Roy, B. Pakhira and S. Sarkar, RSC Adv., 2014, 4, 14210-14214.
33 S. Goswami, S. Paul and A. Manna, RSC Adv., 2013, 3, 1887218877.

34 S. Goswami, S. Das, K. Aich, D. Sarkar and T. K. Mondal, Tetrahedron Lett., 2014, 55, 2695-2699.

35 S. Goswami, S. Das, K. Aich, B. Pakhira, S. Panja, S. K. Mukherjee and S. Sarkar, Org. Lett., 2013, 15, 54125415.

36 J. Fan, M. Hu, P. Zhan and X. Peng, Chem. Soc. Rev., 2013, 42, 29-43.

37 F. Yu, P. Li, P. Song, B. Wang, J. Zhao and K. Han, Chem. Commun., 2012, 48, 2852-2854.

38 B. Liu, F. Zeng, G. Wu and S. Wu, Chem. Commun., 2011, 47, 8913-8915.

39 J. Wen, Y. Xu, H. Li, A. Lu and S. Sun, Chem. Commun., 2015, 51, 11346-11358.

40 L. Pan, S. Sun, A. Zhang, K. Jiang, L. Zhang, C. Dong, Q. Huang, A. Wu and H. Lin, Adv. Mater., 2015, 27, 77827787.

41 Z. Song, T. Lin, L. Lin, S. Lin, F. Fu, X. Wang and L. Guo, Angew. Chem., Int. Ed., 2016, 55, 2773-2777.

42 S. Qu, X. Wang, Q. Lu, X. Liu and L. Wang, Angew. Chem., Int. Ed., 2012, 51, 12215-12218.

43 C. Wang, H. Lin, Z. Xu, Y. Huang, M. G. Humphrey and C. Zhang, ACS Appl. Mater. Interfaces, 2016, 8, 6621-6628.

44 S. Y. Lim, W. Shen and Z. Gao, Chem. Soc. Rev., 2015, 44, 362381.

45 C. Ding, A. Zhu and Y. Tian, Acc. Chem. Res., 2014, 47, 20-30. 46 H. Nie, M. Li, Q. Li, S. Liang, Y. Tan, L. Sheng, W. Shi and S. X.-A. Zhang, Chem. Mater., 2014, 26, 3104-3112.

47 A. Zhao, Z. Chen, C. Zhao, N. Gao, J. Ren and X. Qu, Carbon, 2015, 85, 309-327.

48 G. Li, H. Fu, X. Chen, P. Gong, G. Chen, L. Xia, H. Wang, J. You and Y. Wu, Anal. Chem., 2016, 88, 2720-2726.

49 D. Oushiki, H. Kojima, T. Terai, M. Arita, K. Hanaoka, Y. Urano and T. Nagano, J. Am. Chem. Soc., 2010, 132, 2795-2801.

50 C. Zhao, X. Zhang, K. Li, S. Zhu, Z. Guo, L. Zhang, F. Wang, Q. Fei, S. Luo, P. Shi, H. Tian and W.-H. Zhu, J. Am. Chem. Soc., 2015, 137, 8490-8498.

51 C. Wang, Z. Xu, H. Cheng, H. Lin, M. G. Humphrey and C. Zhang, Carbon, 2015, 82, 87-95.

52 L. Wang and H. S. Zhou, Anal. Chem., 2014, 86, 8902-8905. 53 Q.-Y. Cai, J. Li, J. Ge, L. Zhang, Y.-L. Hu, Z.-H. Li and L.-B. Qu, Biosens. Bioelectron., 2015, 72, 31-36.

54 Y. Liu, H. Li, M. Pei, G. Zhang, L. Hu and J. Han, Talanta, 2013, 115, 190-194.

55 Y. Song, S. Zhu, S. Zhang, Y. Fu, L. Wang, X. Zhao and B. Yang, J. Mater. Chem. C, 2015, 3, 5976-5984. 